\title{
Analysis of Carbon-Carbon Bonding in Small Hydrocarbons and Dicarbon Using Dynamic Orbital Forces: Bond Energies and sigma/pi Partition. Comparison with Sila Compounds.
}

Franck Fuster ${ }^{[b]}$ and Patrick Chaquin*[a]

\begin{abstract}
The CC bonding is analyzed using Dynamic Orbital Forces (DOF) in the series cyclopropane-ethanebenzene-ethylene-acetylene. The sum $\Sigma(D O F)_{t}$ of the DOF over occupied MOs is found linearly correlated to bond energies and thus can be used as a tool for determination of CC bond strength. A partition of bonding into $\sigma$ and $\pi$ components indicates a weakening of the $\sigma$ bonding along the series, mainly due to the decrease of the bonding character of the highest $\sigma \mathrm{MO}$. For $\mathrm{C}_{2}$ molecule, $\Sigma(\mathrm{DOF})_{\mathrm{t}}$ was computed taking into account the four dominant configurations. On the basis of the preceding correlation, the $C_{2}$ bond was found ca. $15 \mathrm{kcal} / \mathrm{mol}$ weaker than that of acetylene, with a $25 \% \sigma$ participation; the bond order of $C_{2}$ can be evaluated at ca. 2.8 if we assume bond orders of 3 for acetylene and 2 for ethylene. Some sila homologs of the preceding carbon compounds have been studied. They exhibit characteristics generally close to the carbon compounds. A quite good correlation between $\Sigma(D O F)_{t}$ and bond energies is also observed.
\end{abstract}

\section{Introduction}

After the pioneer work of Tal and Katriel ${ }^{1}$, the molecular orbital (MO) derivatives with respect to bond length have successfully been used as an index of their bonding character in diatomic molecules. $^{2}$ It can be easily justified, in the case of Hartree-Fock (H-F) canonical MOs, from generalized Koopman's theorem. As a matter of fact, the energy $\varepsilon_{i}$ of the $i^{\text {th }} \mathrm{MO}$ is:

$$
\varepsilon_{i}=E^{0}-E_{i}^{+}
$$

where $E^{0}$ is the H-F energy of the neutral molecule, and $E_{i}^{+}$is the energy of the cation resulting from the removal of one electron from the $i^{\text {th }} \mathrm{MO}$. The derivative with respect to the internuclear distance $R$ yields:

$$
\frac{d \varepsilon_{i}}{d R}=\frac{d E^{0}}{d R}-\frac{d E_{i}^{+}}{d R}
$$

[a] Pr. P. Chaquin

Laboratoire de Chimie Théorique (LCT)

Sorbonne Université, CNRS, F-75005 Paris

E-mail : chaquin@lct.jussieu.fr

[b] Dr. F. Fuster

Laboratoire de Chimie Théorique (LCT)

Sorbonne Université, CNRS, F-75005 Paris 
The MO derivative thus appears as the variation of the forces exerted by electrons on nuclei when one electron is removed, in the approximation of frozen MOs. If the geometry has been optimized at $R=R_{\mathrm{e}}, \mathrm{d} E^{\circ} / \mathrm{d} R=0$ and one gets:

$$
\left(\frac{d \varepsilon_{i}}{d R}\right)_{R=R_{e}}=-\left(\frac{d E_{i}^{+}}{d R}\right)_{R=R_{e}}
$$

A positive value indicates that the electron forces attracting each nucleus toward the other decrease by electron removing from the $\mathrm{i}^{\text {th }} \mathrm{MO}$, which characterizes a bonding character of the corresponding MO. The bond length tends to increase, in order to decrease the total energy. Note that, since the total energy is not the sum of occupied MO energies, the sum of these "orbital forces" is not equal to the total electronic force (contrary to the Bader orbital forces ${ }^{3}$ ). The expression of "dynamic orbital forces" (DOF) for these quantities has been proposed by Averill et al. ${ }^{4}$ and will be adopted it in this work.

These MO derivatives have been also computed in small molecules as an index of a local bonding/antibonding character along a given bond. ${ }^{5}$ Though they don't take into account the electron correlation, these quantities agree with the variation of the bond lengths upon ionization, in a large panel of diatomic and small polyatomic molecules. A semi quantitative relation between the DOF and the relative bond length variation was found. ${ }^{2 a, 5}$ Moreover, it has been shown that the sum of the DOFs over occupied MOs is an index of bond strength and could be used in the interpretation of molecular properties. ${ }^{6}$

In this work, we use the DOFs to analyze CC bonds in paradigmatic hydrocarbons (cyclopropane, ethane, benzene, ethene, ethyne) and dicarbon. The sum of DOF over occupied MOs will be studied in relation to bond energies and bond multiplicity; a partition into $\sigma$ and $\pi$ bonding components will be proposed. The results are compared to some corresponding model sila compounds.

\section{Calculation methods}

The DOFs of hydrocarbons, dicarbon and sila compounds were computed by a small finite CC or SiSi bond length difference (typically 2-8 $10^{-3} \AA$ ) , at the Hartree-Fock (H-F) cc-pVTZ level. The geometries were optimized at the MP2/cc-pVTZ level. For $\mathrm{C}_{2}$, the DOFs were computed at cc-pVQZ/H-F level with a bond length optimized at the CCSD(T)/cc-pVQZ level. It has been shown that the DOFs are essentially independent on the basis set, provided its quality is at least triple zeta. ${ }^{2 a}$ Bond energies were computed at the MP2/cc-pVTZ level. The GAUSSIAN 09 series of programs ${ }^{7}$ was used throughout this work.

\section{Results and discussion}

\section{CC bonding in the series cyclopropane-acetylene}

We first present the results for the sequence cyclopropane, ethane, benzene, ethylene and acetylene, as prototypes of various CC bond strengths and bond multiplicities, from the weak single bond of cyclopropane to the triple bond of acetylene. 
The dynamic orbital forces (DOF) in a.u. are reported in Table 1 for occupied MOs of the valence shells, by order of decreasing energy (the first MO of each column is the HOMO). In the lowest part of the Table, we report sums of DOFs over occupied MOs per CC bond: $\Sigma(\text { DOF })_{t}$, total sum, $\Sigma(\text { DOF })_{\sigma}$ sum over $\sigma$-type MOs and $\Sigma(\mathrm{DOF})_{\pi}$ sum over $\pi$-type MOs; the percent of $\sigma$ bonding is defined as 100 $\Sigma_{\sigma} / \Sigma_{\mathrm{t}}$

Table 1. DOFs (au) with respect to CC bond(s); sums of DOFs over occupied MOs per CC bond: $\Sigma(D O F)_{t}$, total sum; $\Sigma(\mathrm{DOF})_{\sigma}$ sum of DOFs of $\sigma$-type MOs; $\Sigma(\mathrm{DOF})_{\pi}$ sum DOFs of $\pi$-type MOs; $\% \sigma$ : percent of $\Sigma(\mathrm{DOF})_{\sigma}$ in $\Sigma(\mathrm{DOF})_{\mathrm{t}} ; \mathrm{Fb}$ formal bond order; $\mathrm{BE}$, bond energy in $\mathrm{kcal} / \mathrm{mol}$.

\begin{tabular}{|c|c|c|c|c|c|c|c|c|c|}
\hline \multicolumn{2}{|c|}{$\mathrm{C}_{3} \mathrm{H}_{6}$} & \multicolumn{2}{|c|}{$\mathrm{C}_{2} \mathrm{H}_{6}$} & \multicolumn{2}{|c|}{$\mathrm{C}_{6} \mathrm{H}_{6}$} & \multicolumn{2}{|c|}{$\mathrm{C}_{2} \mathrm{H}_{4}$} & \multicolumn{2}{|c|}{$\mathrm{C}_{2} \mathrm{H}_{2}$} \\
\hline MO & DOF & MO & DOF & MO & DOF & MO & DOF & MO & DOF \\
\hline $2 e^{\prime}$ & 0.089 & $1 e_{g}$ & -0.056 & $1 e_{1 g}(\pi)$ & 0.095 & $1 b_{3 u}(\pi)$ & 0.127 & $1 \pi_{\mathrm{u}}$ & 0.118 \\
\hline $1 e^{\prime \prime}$ & -0.059 & $2 \mathrm{a}_{1 \mathrm{~g}}(\sigma)$ & 0.118 & $2 e_{2 g}$ & -0.020 & $1 b_{3 g}$ & -0.087 & $2 \sigma_{\mathrm{g}}$ & 0.009 \\
\hline $2 a^{\prime}{ }_{1}$ & 0.116 & $1 e_{u}$ & 0.061 & $1 a_{2 u}(\pi)$ & 0.225 & $2 a_{g}(\sigma)$ & 0.080 & $1 \sigma_{u}$ & -0.086 \\
\hline $1 a^{\prime \prime}{ }_{2}$ & 0.112 & $1 \mathrm{a}_{2 \mathrm{u}}(\sigma *)$ & -0.050 & $2 e_{1 u}$ & 0.042 & $1 b_{2 u}$ & 0.064 & $1 \sigma_{\mathrm{g}}$ & 0.149 \\
\hline $1 e^{\prime}$ & -0.018 & $1 a_{1 g}(\sigma)$ & 0.128 & $1 b_{2 u}$ & 0.212 & $1 b_{1 u}(\sigma *)$ & -0.069 & & \\
\hline \multirow[t]{5}{*}{$1 a^{\prime}{ }_{1}$} & 0.297 & & & $1 b_{1 u}$ & -0.155 & $1 \mathrm{a}_{\mathrm{g}}(\sigma)$ & 0.161 & & \\
\hline & & & & $2 a_{1 g}$ & 0.143 & & & & \\
\hline & & & & $1 e_{2 g}$ & 0.069 & & & & \\
\hline & & & & $1 e_{1 u}$ & 0.161 & & & & \\
\hline & & & & $1 a_{1 g}$ & 0.319 & & & & \\
\hline \multicolumn{10}{|c|}{ Sum of DOFs per CC bond; $\%$ of $\sigma$ bonding } \\
\hline & $\mathrm{C}_{3} \mathrm{H}_{6}$ & & $\mathrm{C}_{2} \mathrm{H}_{6}$ & & $\mathrm{C}_{6} \mathrm{H}_{6}$ & & $\mathrm{C}_{2} \mathrm{H}_{4}$ & & $\mathrm{C}_{2} \mathrm{H}_{2}$ \\
\hline$\Sigma(\text { DOF })_{\mathrm{t}}$ & 0.368 & & 0.413 & & 0.480 & & 0.521 & & 0.616 \\
\hline$\Sigma(\text { DOF })_{\sigma}$ & 0.372 & & 0.392 & & 0.342 & & 0.267 & & 0.145 \\
\hline$\Sigma(\text { DOF })_{\pi}$ & -0.004 & & 0.020 & & 0.139 & & 0.254 & & 0.471 \\
\hline$\% \sigma$ & 101.0 & & 95.1 & & 71.0 & & 51.2 & & 23.5 \\
\hline \multicolumn{10}{|c|}{ Formal bond order and bonding energy } \\
\hline $\mathbf{F b}$ & $1 \sigma$ & & $1 \sigma$ & & $1 \sigma 0.5 \pi$ & & $1 \sigma 1 \pi$ & & $1 \sigma 2 \pi$ \\
\hline BE & $63.0^{\mathrm{a}}$ & & $90.1^{\mathrm{a}}$ & & $153.6^{b, c}$ & & $174.1^{\mathrm{a}}$ & & $264.1^{a, b}$ \\
\hline
\end{tabular}

${ }^{\mathrm{a}}$ From ref $8 ;{ }^{\mathrm{b}}{ }^{4} \Sigma^{-}$reference state of $\mathrm{CH} ;{ }^{\mathrm{c}} \mathrm{MP} 2 / \mathrm{cc}-\mathrm{pVTZ}$ ZPE corrected.

Relation between bond energy and $\Sigma(D O F)_{t}$. The sum $\Sigma(D O F)_{t}$ of DOFs with respect to a bond is an intrinsic quantity which is assumed to characterize the bond strength, and it is interesting to compare them with experimental values. Nevertheless the bond dissociation energies ${ }^{8}$ (BDE) are not always representative of the bond strength (BE) because they involve the fragments in their ground state ${ }^{9}$. For cyclopropane and ethylene the dissociation into the ground state ${ }^{3} \mathrm{~B}_{1}$ of $\mathrm{CH}_{2}$ indeed corresponds to the breaking of two $\mathrm{C}-\mathrm{C}$ bonds on each carbon atom; but for benzene and acetylene, in which the dissociation into $\mathrm{CH}$ involves the breaking of three bonds on each carbon, the ${ }^{4} \Sigma^{-}$state of $\mathrm{CH}$ (17.1 $\mathrm{kcal} / \mathrm{mol}$ above $\mathrm{GS}^{12}$ ) must be considered. For benzene, the dissociation energy has been computed at the MP2/cc-pVTZ ZPE corrected level. The obtained BE values, reported in the Table 1, are assumed to be characteristic of bond strengths. 
We observe in Fig. 1 a good linear correlation between $\Sigma(D O F)_{t}$ and BE, with a coefficient $r^{2}=0.994$. The slope is 814.6 (1.30 a.u.), which means that a difference of 0.01 a.u. in $\Sigma(D O F)_{t}$ corresponds to a difference of ca. $8 \mathrm{kcal} / \mathrm{mol}$ in BE. This correlation allows to expect that the DOF calculation could be an easy way of bond strength determination, especially in strained systems.

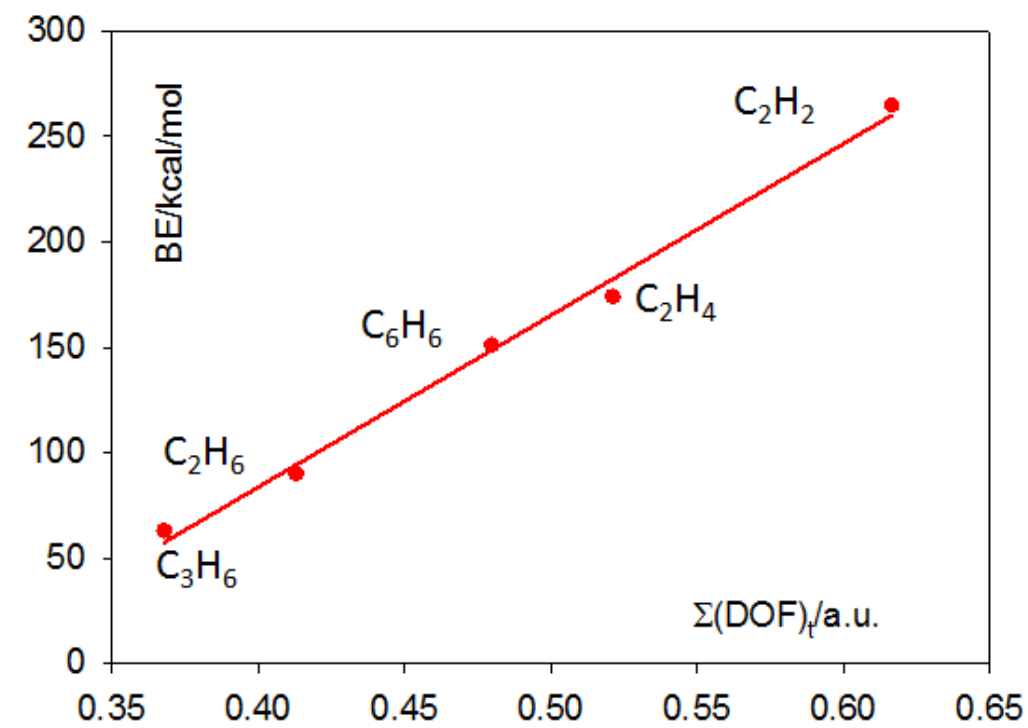

Fig. 1. CC bond energies BE as a function of the sum of the DOFs $\Sigma(D O F)_{t}$

$\sigma / \pi$ ratio in $C C$ bonding. For cyclopropane $\mathrm{C}_{3} \mathrm{H}_{6}$, a' and e' MOs are symmetrical with respect to the CCC plane and contribute to CC $\sigma$ bonding, while a" and e" MOs contribute to $\pi$ bonding. $\Sigma(D O F)_{\pi}$ is slightly negative which indicates that the total $\pi$ contribution is slightly antibonding. On the contrary, in ethane, the $\pi$ contribution, from $e_{g}$ and $e_{u}$ MOs is slightly bonding (5\% of total DOFs). In benzene, the three $\pi$ MOs contribute for ca. $30 \%$ of the bonding which agrees roughly with the formal bonding of $1 \sigma+0.5 \pi$ bonds with $\sigma$ and $\pi$ bonds of comparable strengths.

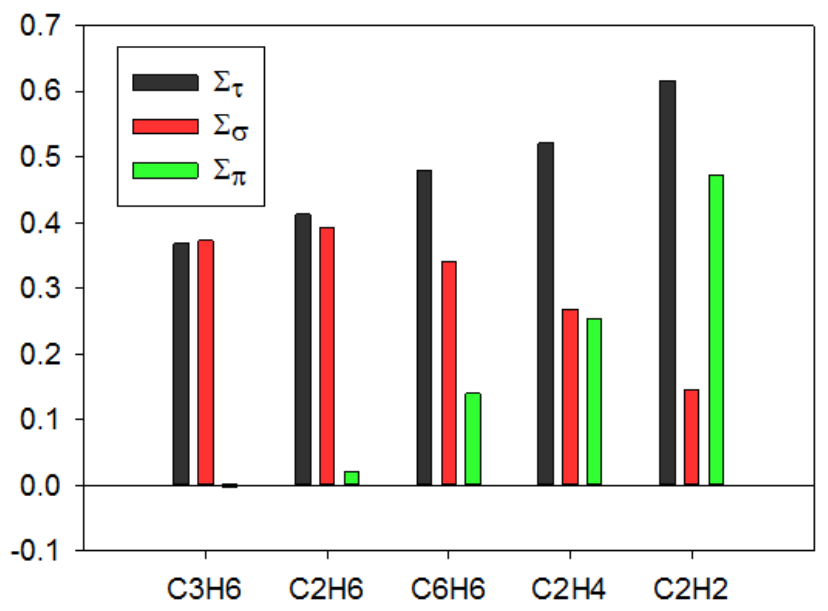

Fig. 2. Relative $\sigma-\pi$ contribution in bonding, from the sum of the corresponding DOFs: $\Sigma_{t}$, total sum; $\Sigma_{\sigma}$ sum of DOFs of $\sigma$-type MOs; $\Sigma_{\pi}$ sum of DOFs of $\pi$-type MOs.

The cases of $\mathrm{C}_{2} \mathrm{H}_{4}$ and $\mathrm{C}_{2} \mathrm{H}_{2}$ contrast with the common idea that the $\sigma$ bonding is stronger that the $\pi$ one because the $B D E$ of $C=C$ is less than twice the BDE of $C-C$. As a matter of fact, the $\pi$ bonding in 
ethylene $\left(\Sigma(\mathrm{DOF})_{\pi}=0.254\right)$ appears almost as strong as the $\sigma$ one $\left(\Sigma(\mathrm{DOF})_{\sigma}=0.267\right)$. In acetylene, each $\pi_{\mathrm{u}}$ electron pair has a bonding contribution (0.236 a.u.) larger than the total $\sigma$ one $\left(\Sigma(\mathrm{DOF})_{\sigma}=\right.$ 0.145 ) which represents only $23.5 \%$ of the total bonding. In Fig. 2, we display the evolution of $\Sigma(\mathrm{DOF})_{\sigma}, \Sigma(\mathrm{DOF})_{\pi}$ and $\Sigma(\mathrm{DOF})_{\mathrm{t}}$, showing the dramatic decrease of the $\sigma$ contribution and the increase of the $\pi$ one along the sequence $\mathrm{C}_{3} \mathrm{H}_{6}-\mathrm{C}_{2} \mathrm{H}_{2}$. Indeed, the $\sigma$ bonds are different, from both hybridization and bond length. In particular, it is worthy to note the evolution in this series of the highest $\sigma \mathrm{MO}$ which becomes less bonding along $\mathrm{CC}$, down to 0.009 in acetylene which is nearly nonbonding. The same MOs become more bonding along $\mathrm{CH}(\mathrm{DOF} / \mathrm{CH}=0.000$ in ethane, 0.024 in ethylene and 0.185 in acetylene).

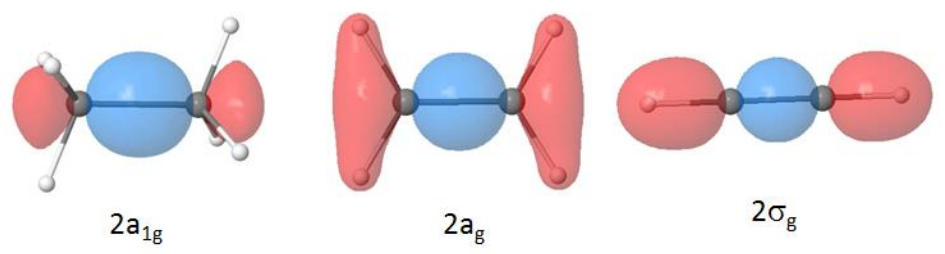

Fig. 3. Highest $\sigma \mathrm{MO}$ of ethane, ethylene and acetylene.

This evolution can be understood by the progressive migration of the electron density from the binding internuclear $\mathrm{CC}$ region to the antibonding region ${ }^{10}$ external to $\mathrm{CC}$ bond (but more $\mathrm{C}-\mathrm{H}$ bonding) as can be seen in Fig. 3. This phenomenon is essentially responsible of the decrease of $\sigma$ bonding $\Sigma(\mathrm{DOF})_{\sigma}$ in this series, as the other $\sigma$-type MOs have a total contribution which varies weakly, ranging from 0.138 a.u. to 0.126 a.u.

Equilibrium bond length and $\sigma / \pi$ bonding. The evolution of the $\sigma / \pi$ bonding with bond order can be related to the variation of the bond length. In this purpose, we computed the variation of the DOFs depending on CC bond length for ethane, ethylene and acetylene as displayed in Fig. 4. Starting from the equilibrium distance of ethane, we observe that, for all three species, the low-lying $\sigma \mathrm{MOs}$ ( $1 \mathrm{a}_{1 \mathrm{~g}}$ for ethane, $1 \mathrm{a}_{\mathrm{g}}$ for ethylene and $1 \sigma_{\mathrm{g}}{ }^{+}$for acetylene) become more bonding, which is due to their $s$ dominant character and thus to the increase of overlap by compression. The DOFs of the higher $\sigma$ MOs (respectively: $2 \mathrm{a}_{1 \mathrm{~g}}, 2 \mathrm{a}_{\mathrm{g}}$ and $2 \sigma_{\mathrm{g}}^{+}$) are weakly decreasing for ethane, and more strongly for ethylene and acetylene. In ethylene and acetylene, the bonding character of the $\pi \mathrm{MO}$ increases as the distance $d_{c c}$ decreases and the $2 p-2 p$ overlap increases. If we compare the bond length equilibrium in the three species, starting from the ethane bond distance: (i) there is no compression for ethane though the increasing of $\Sigma(\mathrm{DOF})_{\sigma}, \Sigma(\mathrm{DOF})_{\pi}$ and $\Sigma(\mathrm{DOF})_{t}$; (ii) for ethylene, we observe a compression with the increase of $\Sigma(\mathrm{DOF})_{\mathrm{t}}$, mainly due to $\Sigma(\mathrm{DOF})_{\pi}$; (iii) in acetylene, there is a further compression though $\Sigma(\mathrm{DOF})_{\sigma}$ decreases but with a strong increase of $\pi$ bonds. This analysis confirms that the bond length is not generally controlled only by the bond strength. As a matter of fact, it has been already stated that the maximum overlap does not ascertain this parameter. ${ }^{11}$ 


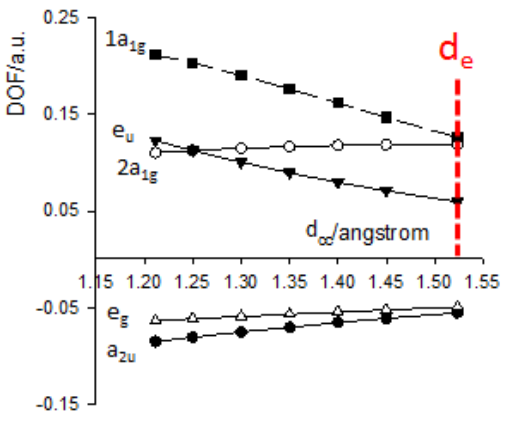

$\mathrm{CH}_{3}-\mathrm{CH}_{3}$

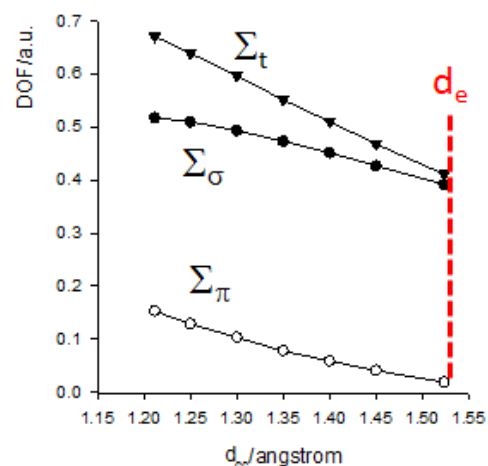

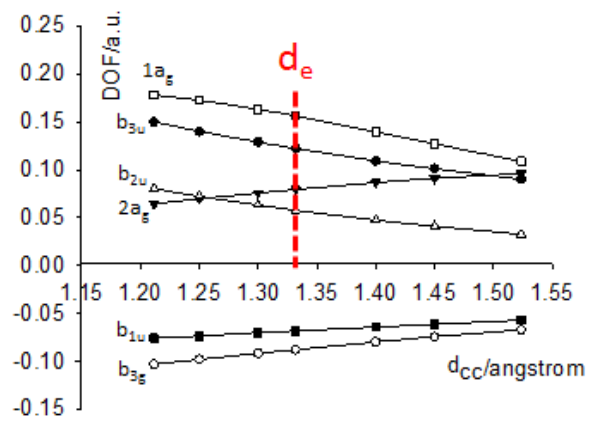

$\mathrm{CH}_{2}=\mathrm{CH}_{2}$

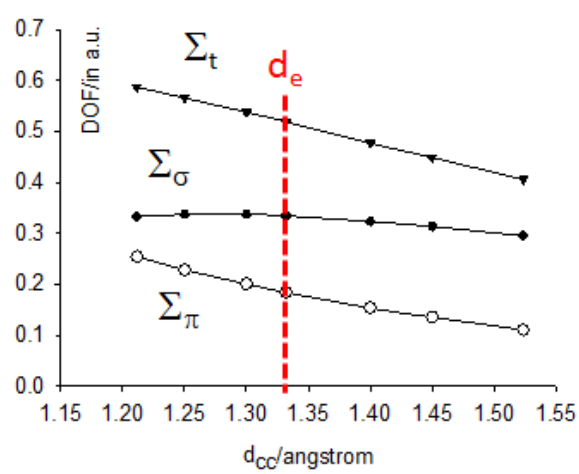

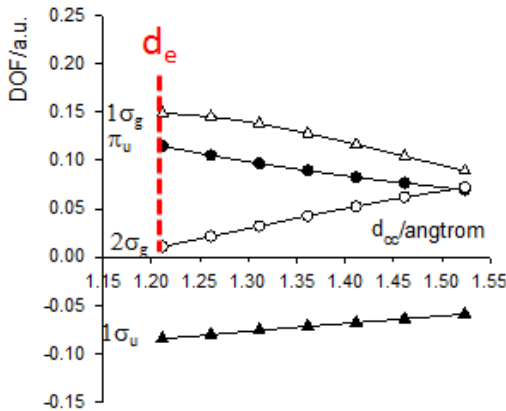

$\mathrm{CH} \equiv \mathrm{CH}$

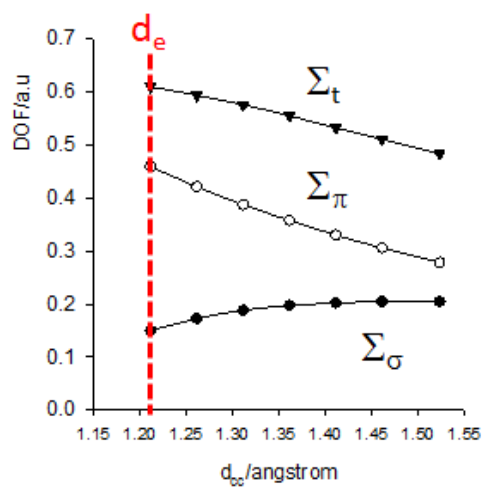

Fig 4. DOF variations as functions of $C C$ distance $d_{C c}$ for ethane, ethylene, acetylene; $d_{\mathrm{e}}$ : equilibrium distance.

\section{Dicarbon $\mathrm{C}_{2}$}

Dealing with $\mathrm{C}_{2}$, a difficulty arises from the fact that its ground state is not mono-configurational. We will use the four dominant configurations reported by Hermann and Frenking, ${ }^{12}$ referred to as conf1conf4 in Table 2.

Both conf1 and conf2 have been computed at the H-F/cc-pVQZ level. The corresponding MO levels and their DOFs are displayed in Fig. 5 with the graphical representation of $\sigma$ MOs. A remarkable result is that the DOFs of the corresponding MOs are close one to another in both conf1 and conf2, though different electron occupancies and significant differences in energy. The $2 \sigma_{\mathrm{g}}{ }^{+} \mathrm{MO}$ is found slightly antibonding in conf1 (DOF $=-0.003$ a.u.) and strictly non-bonding in conf2. This may be surprising because this MO does not exhibit a nodal plane cutting the bond. Nevertheless, similar results have been already reported for similar MOs arising from an "inverted" in-phase overlap, namely the overlap of two $s+p$ hybrids by their smaller lobe. Such MOs can be moderately bonding or even antibonding according to the case. For example, the highest $\sigma_{\mathrm{g}}{ }^{+} \mathrm{MO}$ is slightly bonding in $\mathrm{N}_{2}$ (DOF $=0.047$ a.u.), but slightly antibonding in $P_{2}$ (DOF $=-0.008$ a.u. $)^{2 a}$. An increase in bond length of the ${ }^{2} \Sigma_{\mathrm{g}}{ }^{+}$anion $\mathrm{C}_{2}^{-}$with respect to the neutral molecule $\left(1.2682 \AA\right.$ vs. $1.2458 \AA{ }^{13}$ agrees with a slightly antibonding character of this $\mathrm{MO}$.

Because all attempts of H-F convergence on conf3 and conf4 have failed, we used for these configurations the mean DOF values of conf1 and conf2. It can be justified by the fact that the DOFs 
appear to be rather independent on the configuration. This could result in some error, presumably weak due to their weak weight in the total wave function.

Table 2. DOF (au) of MOs of the four dominant configurations of $\mathrm{C}_{2}$; nelec: electron occupancy; Fb formal bond order; total: sum of the weighted values of conf1-conf4; sums of DOFs over occupied MOs: $\Sigma(D O F)_{t}$, total sum; $\Sigma(\text { DOF })_{\sigma}$ sum of DOFs of $\sigma$-type MOs; $\Sigma(\text { DOF })_{\pi}$ sum DOFs of $\pi$-type MOs; $\% \sigma$ : percent of $\Sigma(D O F)_{\sigma}$ in $\Sigma(D O F)_{t} ; B E$ bond energy computed from Fig. 1 correlation in $\mathrm{kcal} / \mathrm{mol}$.

\begin{tabular}{|c|c|c|c|c|c|c|c|c|c|}
\hline \multirow[t]{2}{*}{ MO } & \multicolumn{2}{|c|}{$\begin{array}{l}\text { conf } 1 \\
\text { (71\%) }\end{array}$} & \multicolumn{2}{|c|}{$\begin{array}{c}\text { conf } 2 \\
(13.6 \%)\end{array}$} & \multicolumn{2}{|c|}{$\begin{array}{l}\text { conf } 3 \\
(6.0 \%)\end{array}$} & \multicolumn{2}{|c|}{$\begin{array}{l}\text { conf } 4 \\
(2.2 \%)\end{array}$} & \\
\hline & DOF(1) & nelec & $\operatorname{DOF}(2)$ & nelec & DOF(3) & nelec & DOF(4) & nelec & \\
\hline $1 \pi_{\mathrm{g}}$ & -0.146 & 0 & -0.140 & 0 & -0.143 & 1 & -0.143 & 2 & \\
\hline $2 \sigma_{\mathrm{g}}^{+}$ & -0.003 & 0 & 0.000 & 2 & -0.001 & 1 & -0.001 & 0 & \\
\hline $1 \pi_{\mathrm{u}}$ & 0.122 & 4 & 0.111 & 4 & 0.116 & 3 & 0.116 & 2 & \\
\hline $1 \sigma_{u}^{+}$ & -0.138 & 2 & -0.130 & 0 & -0.134 & 1 & -0.134 & 2 & \\
\hline $1 \sigma_{\mathrm{g}}^{+}$ & 0.188 & 2 & 0.196 & 2 & 0.192 & 2 & 0.192 & 2 & \\
\hline \multicolumn{10}{|c|}{ Formal bond order } \\
\hline & \multicolumn{2}{|c|}{ conf1 } & \multicolumn{2}{|c|}{ conf2 } & \multicolumn{2}{|c|}{ conf3 } & \multicolumn{2}{|c|}{ conf4 } & Total \\
\hline $\mathrm{Fb}$ & \multicolumn{2}{|c|}{$2 \pi$} & \multicolumn{2}{|c|}{$2 \sigma+2 \pi$} & \multicolumn{2}{|c|}{$1 \sigma+1 \pi$} & \multicolumn{2}{|l|}{0} & $0.36 \sigma+1.89 \pi$ \\
\hline \multicolumn{10}{|c|}{ Sums of DOFs ; \% of $\sigma$ bonding } \\
\hline & \multicolumn{2}{|c|}{ conf1 } & \multicolumn{2}{|c|}{ conf2 } & \multicolumn{2}{|c|}{ conf3 } & \multicolumn{2}{|c|}{ conf4 } & Total \\
\hline$\Sigma(\text { DOF })_{\sigma}$ & \multicolumn{2}{|c|}{0.101} & \multicolumn{2}{|c|}{0.392} & \multicolumn{2}{|c|}{0.249} & \multicolumn{2}{|c|}{0.097} & 0.153 \\
\hline$\Sigma(\text { DOF })_{\pi}$ & \multicolumn{2}{|c|}{0.487} & \multicolumn{2}{|c|}{0.445} & \multicolumn{2}{|c|}{0.205} & \multicolumn{2}{|c|}{-0.034} & 0.450 \\
\hline$\Sigma(\text { DOF })_{\mathrm{t}}$ & \multicolumn{2}{|c|}{0.587} & \multicolumn{2}{|c|}{0.836} & \multicolumn{2}{|c|}{0.454} & \multicolumn{2}{|c|}{0.063} & 0.603 \\
\hline$\% \sigma$ & \multicolumn{2}{|c|}{17} & \multicolumn{2}{|c|}{46.8} & \multicolumn{2}{|c|}{54.8} & \multicolumn{2}{|c|}{153} & 25.3 \\
\hline & & & & Bond & ng energ & & & & \\
\hline BE & 236 & & 438 & & 12 & & - & & 249.1 \\
\hline
\end{tabular}

In Table 2, we report for each configuration the sums $\Sigma(\mathrm{DOF})_{\sigma}, \Sigma(\mathrm{DOF})_{\pi}$ and $\Sigma(\mathrm{DOF})_{\mathrm{t}}$ and the percent of $\sigma$ bonding, as defined in the preceding section.
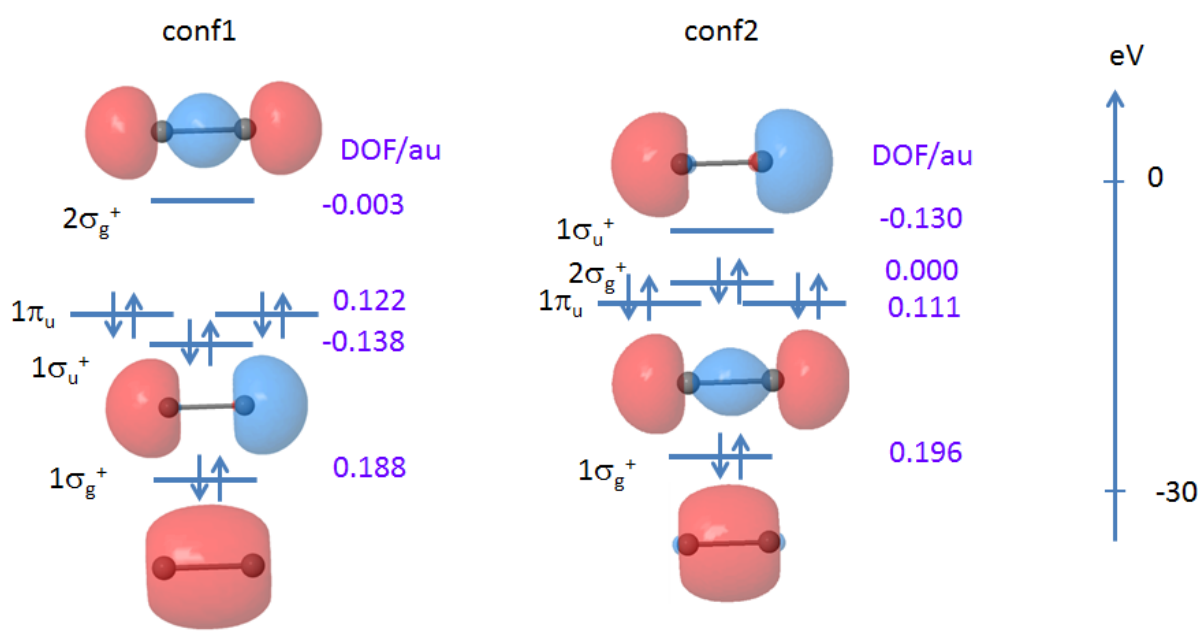

Fig 5. MO diagram and DOFs of the two dominant configurations of $C_{2}$. 
The dominant configuration (conf1) is formally a double $\pi$ bond, but has actually a $17 \% \sigma$ participation due to the fact that the bonding $1 \sigma_{\mathrm{g}}{ }^{+}$(DOF $=0.188 \mathrm{a}$.u.) is only partly canceled by its antibonding counterpart $1 \sigma_{u}{ }^{+}$(DOF $=-0.138$ a.u.). Conf2 has formally a $2 \sigma+2 \pi$ quadruple bond and a $\sigma$ contribution of $46.8 \%$, but arising only from the strongly bonding $1 \sigma_{\mathrm{g}}{ }^{+} \mathrm{MO}$ (DOF $=0.196$ a.u.), because $2 \sigma_{\mathrm{g}}{ }^{+}$, though formally bonding, is actually non-bonding ( $\mathrm{DOF}=0.000$ ).

Using the correlation of Fig. 1, a BE of 236.1 and $127.7 \mathrm{kcal} / \mathrm{mol}$ is found for conf2 and conf3 respectively. Though it lies out of the range of Fig. 1, an extrapolated BE value of $438.9 \mathrm{kcal} / \mathrm{mol}$ can be proposed for conf $2\left(\Sigma(\mathrm{DOF})_{\mathrm{t}}=0.836\right)$, whereas conf4 should be practically non-bonded $\left(\Sigma(\mathrm{DOF})_{\mathrm{t}}=\right.$ $0.063)$.

The $\Sigma$ (DOF) quantity has been previously defined for a single configuration system and there is no evident way to compute rigorously the corresponding quantity for a multiconfiguration wave function. Nevertheless, a simple and intuitive approach consists in considering that $\Sigma$ (DOF) of $C_{2}$ can be described, at least approximately, as a weighted sum of $\Sigma(\mathrm{DOF})$ of each configuration. Assuming that the DOFs are nearly the same in all configurations, it amounts to use non integer occupancies in a single configuration. The "total" values reported in Table 2 are thus the sums of the corresponding quantities weighted by the participation of each configuration. Doing so, a 0.603 a.u. value of $\Sigma(D O F)_{t}$ is found for $\mathrm{C}_{2}$, corresponding to $\mathrm{BE}=249.1 \mathrm{kcal} / \mathrm{mol}$, with $25.3 \%$ of $\sigma$ participation. This $\mathrm{BE}$ is slightly less than that of acetylene $\left(\Sigma(D O F)_{t}=0.616\right.$ a.u.; $\left.B E=264.1 \mathrm{kcal} / \mathrm{mol}\right)$. It can be noted that the dominant configuration alone (conf1) corresponds to a $\mathrm{BE}$ close to its total value $\left(\Sigma(\mathrm{DOF})_{\mathrm{t}}=0.587 ; \mathrm{BE}\right.$ $=236.1 \mathrm{kcal} / \mathrm{mol})$.

How many bonds in $\mathbf{C}_{\mathbf{2}}$ ? Like many other irreplaceable notions in chemistry, the bond multiplicity is a fuzzy concept. It has a long history beginning by the count of electron pairs ${ }^{14}$, continued by population analyses by Coulson ${ }^{15}$ or Mulliken ${ }^{16}$ methods; it gave rise to various modern developments ${ }^{17}$ and recent approaches based on quantum chemical topology. ${ }^{18}$

In particular, the bond multiplicity of dicarbon is highly controversial. ${ }^{12,19}$ Indeed, the answer to this question depends on the criterion used as a base of calculation.

For organic chemists, the bond multiplicity can be defined by the number of possible additions of molecules $\mathrm{X}_{2}$ without CC breaking, at least formally. Following this criterion, one can consider that $\mathrm{C}_{2}$ possesses a triple unsaturation and thus a quadruple bond.

For quantum chemists, a simple determination consists in counting bonding $\left(n_{b}\right)$ and antibonding $\left(n^{*}\right)$ electrons and setting $\mathrm{Nb}=1 / 2\left(\mathrm{n}_{\mathrm{b}}-\mathrm{n}^{*}\right)$. This formula corresponds to the formal bond multiplicity $\mathrm{Nb}$ reported in Tables 1 and 2. But the real situation is less clear, because the bonding/antibonding character may vary in an important range. For instance, some formally bonding MOs can be actually weakly bonding or non-bonding: as already seen, it is the case for the $2 \sigma_{\mathrm{g}}{ }^{+} \mathrm{MO}$ in $\mathrm{C}_{2}$. In addition, this definition is problematic if the wave function is not mono-configurational, which also happens for $C_{2}$. Considering the weighted bond order and of each leading configuration, we can assign to $C_{2}$ a formal bond order of 2.25 (cf. Table 2). Other quantum chemists consider, from VB calculations, that $\mathrm{C}_{2}$ possesses a quadruple bond, the fourth one arising from the overlap of two $s+p$ hybrids by their smaller lobe. The energy of this "inverted bond" was found of ca. $20 \mathrm{kcal} / \mathrm{mol}$. ${ }^{20}$ This conclusion is 
supported by the compared magnetic shielding of $C_{2}$ and acetylene ${ }^{21}$ and also by a recent study using a symmetry-broken wave function, yielding to an effective bond order of 3.36. ${ }^{22}$

On the other hand, it is concluded from interference energy calculation that $C_{2}$ possesses a triple bond. ${ }^{23}$ From domain-averaged Fermi holes studied by Ponec et al., the $\sigma$ system of $C_{2}$ appears similar to that of $\mathrm{Be}_{2}$, while its $\pi$ system is similar to that of acetylene. These authors conclude that "classification of the bonding in this molecule in terms of classical concepts of bond order or bond multiplicity is highly questionable". ${ }^{24}$

Physical-chemists may prefer to use measurable quantity-based criteria. The bond energy is another possible criterion for the attribution of a bond multiplicity. It is again problematic for $\mathrm{C}_{2}$ because there is a doubt on the state of atomic carbon to be considered after bond breaking, ${ }^{3} \mathrm{P}$ ground state or ${ }^{5} \mathrm{~S}$ excited state. If we assume that the $\Sigma(\mathrm{DOF})_{\mathrm{t}}$ value is a good index of intrinsic bond energy, the BE of $C_{2}\left(\Sigma(D O F)_{t}=0.603\right.$ a.u. $)$ is found, from Fig. 1 , a little less than that of acetylene $\left(\Sigma(D O F)_{t}=\right.$ 0.616 a.u.) by about $15 \mathrm{kcal} / \mathrm{mol}$.

One can also consider the force constant of the bond, responsible from the fact that valence modes in vibration spectroscopy have frequencies in clearly different parts of spectra, according to the bond multiplicity. This criterion also agrees with $\Sigma(\mathrm{DOF})_{\mathrm{t}}$ values which are correlated with the force constants computed by Hermann et Frenking ${ }^{12}$ for ethane, ethylene and acetylene as can be seen in Fig. 6a. Nevertheless, the force constant $k_{c c}$ of $C_{2}$ is below its expected value for $\Sigma(D O F)_{t}=0.603$ a.u. High level calculations of forces constants in the same series support a bond strength of $C_{2}$ halfway between that of a single and a triple bond. ${ }^{25}$

Finally, if we assume that the bond multiplicity is exactly 1 in ethane, 1.5 in benzene, 2 in ethylene and 3 in acetylene, we observe in Fig. $6 \mathrm{~b}$ that $\Sigma(\mathrm{DOF})_{\mathrm{t}}$ is fairly linearly correlated to these numbers. From its $\Sigma(D O F)_{t}$ value, the bond order of $C_{2}$ can be estimated to ca. 2.8 on this basis.

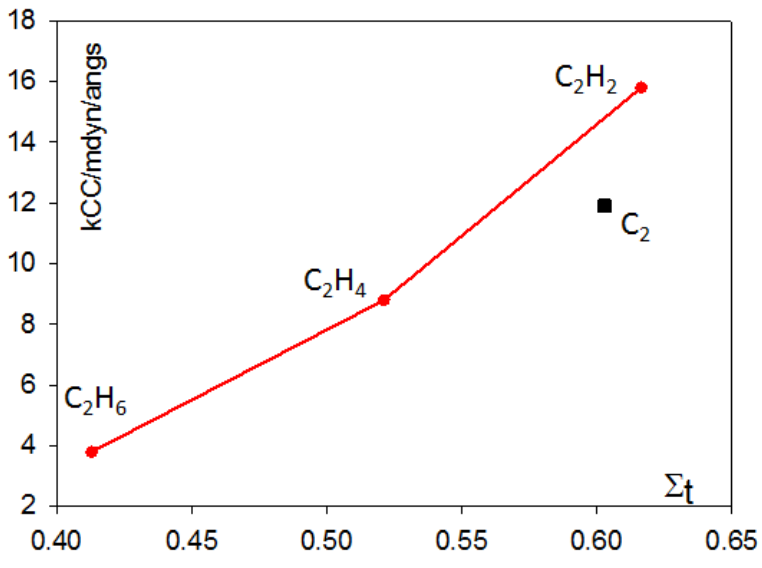

(a)

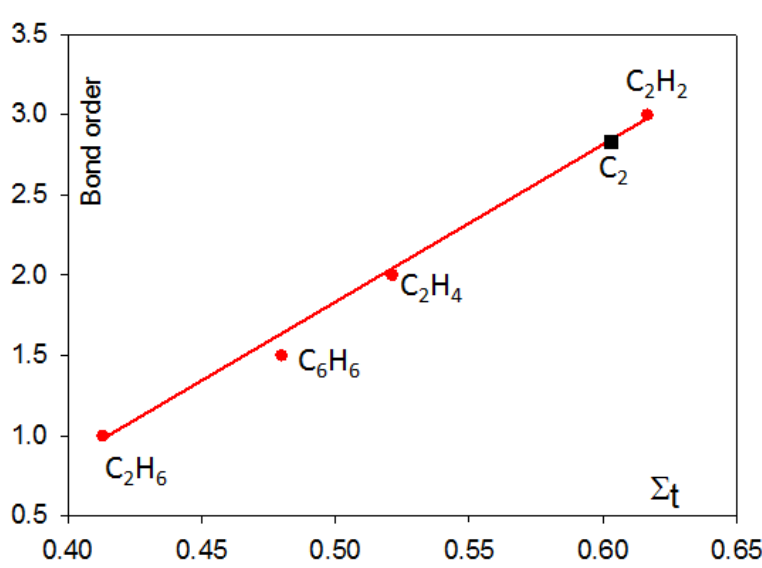

(b)

Fig. 6. (a) Force constants $k_{\mathrm{cc}}$ and (b) formal bond order as functions of the sum $\Sigma(D O F)_{t}$.

\section{Comparison with sila compounds}

Our aim in this section is to compare the DOFs of Si-Si and C-C bonds. We first examine three silicon compounds $\left(\mathrm{Si}_{2} \mathrm{H}_{6}, \mathrm{Si}_{2} \mathrm{H}_{4}\right.$ and $\left.\mathrm{Si}_{2} \mathrm{H}_{2}\right)$ with the same structure as corresponding hydrocarbons, whilst they are not the most stable. As a matter of fact, the most stable structure of $\mathrm{Si}_{2} \mathrm{H}_{2}$ has a double $\mathrm{H}$ 
bridge ${ }^{26}$, and $\mathrm{Si}_{2} \mathrm{H}_{4}$ has pyramidal $\mathrm{H}_{2} \mathrm{Si}$-Si groups. ${ }^{27}$ Then we will examine $\mathrm{Si}_{2}$ and $\mathrm{Si}_{2} \mathrm{H}_{2}$ in its most stable geometry.

$\mathrm{Si}_{2} \mathrm{H}_{6}$, planar $\mathrm{Si}_{2} \mathrm{H}_{4}$, linear $\mathrm{Si}_{2} \mathrm{H}_{2}$. A first observation is that the DOF values are 2-3 times smaller than for hydrocarbons (Table 3). The decrease of the DOFs going down a column has been already pointed out. ${ }^{2 a}$ We observe again that the highest $\sigma$ MO (resp. $2 \mathrm{a}_{1 \mathrm{~g}}, 2 \mathrm{a}_{\mathrm{g}}, 2 \sigma_{\mathrm{g}}$ ) becomes less bonding along the series, less markedly than for the carbon series. The $\Sigma_{\sigma}$ participation to the bond decreases with the bond multiplicity and its percent of total bonding is very close to that observed in hydrocarbons (Figure 7). The sum $\Sigma_{\mathrm{t}}$ increases with the formal bond multiplicity, but no longer linearly. Finally, the DOF properties of these compounds are quite similar to those of the corresponding hydrocarbons.

Table 3. DOFs(au) with respect to SiSi bond(s); sums of DOFs over occupied MOs per SiSi bond: $\Sigma_{\mathrm{t}}$, total sum; $\Sigma_{\sigma}$ sum of DOFs of $\sigma$-type MOs; $\Sigma_{\pi}$ sum DOFs of $\pi$-type MOs; $\% \sigma$ : percent of $\Sigma_{\sigma}$ in $\Sigma_{t}$; BE bonding energy (kcal/mol).

\begin{tabular}{|c|c|c|c|c|c|c|c|c|c|}
\hline MO & $\mathrm{Si}_{2} \mathrm{H}_{6}$ & MO & $\begin{array}{c}\mathrm{Si}_{2} \mathrm{H}_{4} \\
\text { planar }\end{array}$ & MO & $\begin{array}{c}\mathrm{Si}_{2} \mathrm{H}_{2} \\
\text { linear }\end{array}$ & MO & $\begin{array}{c}\mathrm{Si}_{2} \mathrm{H}_{2} \\
\text { dibridged }\end{array}$ & MO & $\mathrm{Si}_{2}$ \\
\hline $2 a_{1 g}$ & 0.050 & $1 b_{3 u}(\pi)$ & 0.049 & $1 \pi_{\mathrm{u}}$ & 0.044 & $3 a_{1}$ & 0.026 & $1 \pi_{\mathrm{u}}$ & 0.028 \\
\hline $1 e_{g}$ & -0.010 & $2 \mathrm{a}_{\mathrm{g}}(\sigma)$ & 0.034 & $2 \sigma_{\mathrm{g}}$ & 0.017 & $2 a_{1}$ & 0.020 & $2 \sigma_{\mathrm{g}}$ & 0.006 \\
\hline $1 e_{u}$ & 0.014 & $1 b_{3 g}$ & -0.018 & $1 \sigma_{\mathrm{u}}$ & -0.029 & $1 b_{2}$ & -0.044 & $1 \sigma_{u}$ & -0.039 \\
\hline $1 a_{2 u}$ & -0.016 & $1 b_{2 u}$ & 0.005 & $1 \sigma_{\mathrm{g}}$ & 0.045 & $1 b_{1}$ & 0.070 & $1 \sigma_{\mathrm{g}}$ & 0.083 \\
\hline \multirow[t]{2}{*}{$1 a_{1 g}$} & 0.046 & $1 b_{1 u}(\sigma *)$ & -0.023 & & & $1 a_{1}$ & 0.047 & & \\
\hline & & $1 a_{g}$ & 0.050 & & & & & & \\
\hline \multicolumn{10}{|c|}{ Sum of DOFs and \% of $s$ bonding } \\
\hline & $\mathrm{Si}_{2} \mathrm{H}_{6}$ & & $\begin{array}{c}\mathrm{Si}_{2} \mathrm{H}_{4} \\
\text { planar }\end{array}$ & & $\begin{array}{l}\mathrm{Si}_{2} \mathrm{H}_{2} \\
\text { linear }\end{array}$ & & $\begin{array}{c}\mathrm{Si}_{2} \mathrm{H}_{2} \\
\text { dibridged }\end{array}$ & & \\
\hline$\Sigma(\text { DOF })_{t}$ & 0.175 & $\Sigma_{\mathrm{t}}$ & 0.196 & $\Sigma_{\mathrm{t}}$ & 0.243 & $\Sigma_{t}$ & 0.234 & $\Sigma_{\mathrm{t}}$ & 0.152 \\
\hline$\Sigma(\text { DOF })_{\sigma}$ & 0.160 & $\Sigma_{\sigma}$ & 0.098 & $\Sigma_{\sigma}$ & 0.067 & $\Sigma_{\sigma}$ & 0.145 & $\Sigma_{\sigma}$ & 0.098 \\
\hline$\Sigma(\text { DOF })_{\pi}$ & 0.015 & $\Sigma_{\pi}$ & 0.098 & $\Sigma_{\pi}$ & 0.176 & $\Sigma_{\pi}$ & 0.091 & $\Sigma_{\pi}$ & 0.055 \\
\hline$\% \sigma$ & 91.4 & & 50.0 & & 27.6 & & 61.3 & & 64.5 \\
\hline \multicolumn{10}{|c|}{ Bonding energy } \\
\hline BE & $76.9^{\mathrm{a}}$ & & $99.4^{a}$ & & $117.0^{\mathrm{a}}$ & & $113.4^{b}$ & & $74.4^{c}$ \\
\hline
\end{tabular}

${ }^{\mathrm{a}} \mathrm{MP2} / \mathrm{cc}-\mathrm{pVTZ}{ }^{\mathrm{a}}$ From regression equation $\mathrm{y}=506.1 \mathrm{x}-5.00$ (Fig. 7) ${ }^{\mathrm{c}}$ From ref 28

$S i_{2}$. The molecule $\mathrm{Si}_{2}$ is ${ }^{3} \Sigma_{\mathrm{g}}^{-}$in its ground state with a bond energy of $74.4 \mathrm{kcal} / \mathrm{mol} .^{28}$ We report in Table 3 the results corresponding to the dominant configuration $1 \sigma_{\mathrm{g}}{ }^{2} 1 \sigma_{\mathrm{u}}{ }^{2} 2 \sigma_{\mathrm{g}}{ }^{2} 1 \pi_{\mathrm{u}}{ }^{2}$. Contrary to $C_{2}$, the bonding is essentially provided by $\sigma \mathrm{MOs}(64.5 \%)$. Though the bond order of $\mathrm{Si}_{2}$ is formally $1 \sigma$ $1 \pi$, its $\mathrm{BE}$ is slightly less than that of the single bond of $\mathrm{Si}_{2} \mathrm{H}_{6}$, mainly due to a weaker $\sigma$ bond. 


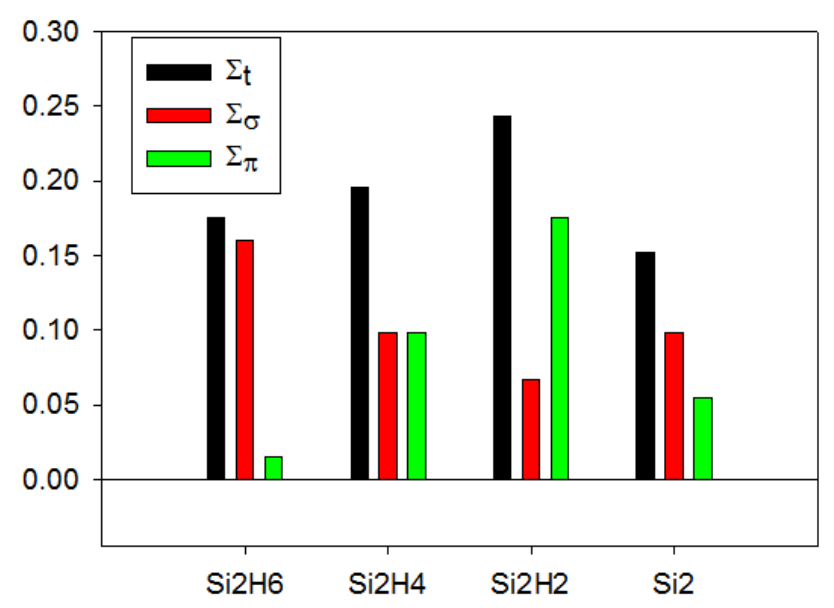

Figure 7. Relative $\sigma-\pi$ contribution in bonding, from the sum of the corresponding DOFs: $\Sigma_{\mathrm{t}}$, total sum; $\Sigma_{\sigma}$ sum of DOFs of $\sigma$-type MOs; $\Sigma_{\pi}$ sum of DOFs of $\pi$-type MOs.

From the four preceding molecules, we observe in Fig. 8 a quite good linear correlation between $\Sigma(D O F)_{t}$ and $B E$, with a coefficient $r^{2}$ equal to 0.934 .

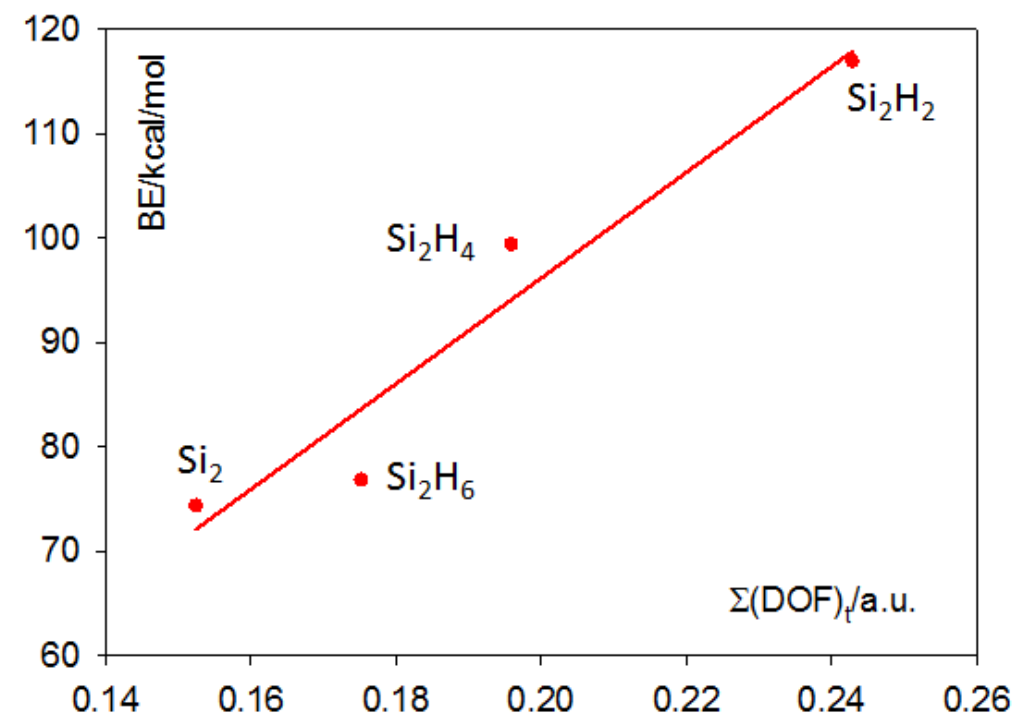

Fig. 8. SiSi bond energies $B E$ as a function of the sum of the DOFs $\Sigma(D O F)_{t}$

Doubly-bridged $\mathrm{Si}_{2} \mathrm{H}_{2}$. The most stable geometry of $\mathrm{Si}_{2} \mathrm{H}_{2}$ is a $\mathrm{C}_{2 v}$ with a double hydrogen bridge structure. Due to cyclic SiHSi patterns, the Si-Si bond length cannot be varied without variation of Si$\mathrm{H}$ distances and/or angle(s). We choose to keep constant the distances Si-H. The value of $\Sigma(\mathrm{DOF})_{\mathrm{t}}$ allows to propose a Si-Si bond energy of ca. $113 \mathrm{kcal} / \mathrm{mol}$ using the correlation of Fig. 8. There is no longer symmetry defined $\sigma$ and $\pi$ MOs, and their attribution has been done "visually": a MO has been considered as $\sigma$ if it has a significant density on the Si-Si line. Though the BE of doubly-bridged molecule is close to that of the linear one, they strongly differ by the percent of $\sigma$ bonding. 


\section{Conclusion}

It has been shown that the sum $\Sigma(\mathrm{DOF})_{\mathrm{t}}$ of the dynamic orbital forces (DOF) over occupied MOs is tightly related linearly to the $\mathrm{CC}$ bond strength and constitutes a tool for the determination of bond energies. A partition of $\sigma$ and $\pi$ components reveals that the $\sigma$ bonding decreases along the series cyclopropane-ethane-benzene-ethylene-acetylene, both in relative and absolute value, from $101 \%$ in cyclopropane to ca. $23.5 \%$ in acetylene.

The sum $\Sigma(D O F)_{t}$ has been evaluated for each of the four dominant conformations of $C_{2}$. The resulting weighted value yields an intrinsic BE of ca. $249 \mathrm{kcal} / \mathrm{mol}$, about $15 \mathrm{kcal} / \mathrm{mol}$ below that of acetylene, with a $25 \% \sigma$ participation to the bonding. From another point of view, if we assume that the bond order is 1 for ethane, 2 for ethylene and 3 for acetylene, the bond order of $C_{2}$ can be evaluated to ca. 2.8 on the basis of its $\Sigma(D O F)_{t}$ value.

The DOFs of three sila compounds $\mathrm{Si}_{2} \mathrm{H}_{6}, \mathrm{Si}_{2} \mathrm{H}_{4}$ and $\mathrm{Si}_{2} \mathrm{H}_{2}$ with the same structure as the corresponding hydrocarbons have been reported. Their main characteristics are quite similar to carbon compounds. By contrast, in $\mathrm{Si}_{2}$ and doubly-bridged $\mathrm{Si}_{2} \mathrm{H}_{2}$ the $\mathrm{Si}$-Si bonding is more than $60 \%$ of $\sigma$ type.

Acknowledgement. The authors are grateful to a Referee who suggested the study of doublebridged $\mathrm{Si}_{2} \mathrm{H}_{2}$.

Keywords : Orbital Forces; CC bond energy; Hydrocarbons; Dicarbon; Silanes.

\footnotetext{
1 T. Tal, J. Katriel, Theoret. Chim. Acta 1977, 46 173-181.

${ }^{2}$ (a) P. Chaquin, Y. Canac, C. Lepetit, D. Zargarian, R. Chauvin, Int. J. Quant. Chem. 2016, 116, 1285-1295; (b) F.M.Bickelhaupt, J. K. Nagle, W.L. Klemm, J. Phys. Chem. A 2008, 112, 2437-2446; (c) P.J. Robinson, A.N. Alexandrova, J. Phys. Chem. A 2015, 119, 12862-12867.
}

${ }^{3}$ (a) R.F. W. Bader, A.D. Bandrauk, J. Chem. Phys.1968, 49, 1653-1665; (b) R. F. W Bader, J. Keaveny, P. E. Cade, J. Chem. Phys., 1967, 47,3381-3402. ; c) P. E. Cade, R.F.W. Bader, W.H. Henneker, I. Keaveny, J. Chem. Phys. 1969, 50, 5313-5333.

${ }^{4}$ F.W. Averill, G. S Painter, Phys. Rev. B 1986, 34(4) 2088-2095.

${ }^{5}$ Chaquin, F. Fuster, F. Volatron, Int. J. Quant. Chem 2018, 118, 25658-25659.

${ }^{6}$ (a) Y. Yamaguchi, R.B. Remington, J.F. Gaw, H. F. Schaefer III, G. Frenking, Chem. Phys. 1994, 180, 55-70; (b) Y. Yamaguchi, R.B. Remington, J.F. Gaw, H. F. Schaefer III, G. Frenking, J. Chem. Phys. 1993, 98 (11), 8749-8760; (c) Yamaguchi, B. J. DeLeeuw, C. A. Richards, Jr., H. F. Schaefer III, G. Frenking, J. Am. Chem. Soc. 1994, 116, 1192211930

${ }^{7}$ Gaussian 09, Revision A.01, M. J. Frisch, G. W. Trucks, H. B. Schlegel, G. E. Scuseria, M. A. Robb, J. R. Cheeseman, G. Scalmani, V. Barone, B. Mennucci, G. A. Petersson, H. Nakatsuji, M. Caricato, X. Li, H. P. Hratchian, A. F. Izmaylov, J. Bloino, G. Zheng, J. L. Sonnenberg, M. Hada, M. Ehara, K. Toyota, R. Fukuda, J. Hasegawa, M. Ishida, T. Nakajima, Y. Honda, O. Kitao, H. Nakai, T. Vreven, J. A. Montgomery, Jr., J. E. Peralta, F. Ogliaro, M. Bearpark, J. J. Heyd, E. Brothers, K. N. Kudin, V. N. Staroverov, R. Kobayashi, J. Normand, K. 
Raghavachari, A. Rendell, J. C. Burant, S. S. Iyengar, J. Tomasi, M. Cossi, N. Rega, J. M. Millam, M. Klene, J. E. Knox, J. B. Cross, V. Bakken, C. Adamo, J. Jaramillo, R. Gomperts, R. E. Stratmann, O. Yazyev, A. J. Austin, R. Cammi, C. Pomelli, J. W. Ochterski, R. L. Martin, K. Morokuma, V. G. Zakrzewski, G. A. Voth, P. Salvador, J. J. Dannenberg, S. Dapprich, A. D. Daniels, Ö. Farkas, J. B. Foresman, J. V. Ortiz, J. Cioslowski, D. J. Fox, Gaussian, Inc., Wallingford CT, 2009.

${ }^{8}$ S.J. Blanksby, G. B. Ellison, Acc. Chem. Res., 2003, 36 (4), 255-263

${ }^{9}$ D. M. Andrada, José Luis Casals-Sainz, Á. M. Pendás, G. Frenking, Chem. Eur. J. 2018, 24, 9083 - 9089

${ }^{10}$ T. J. Berlin, Chem. Phys. 1951, 19(2), 208-213

${ }^{11}$ A. Krap p, F. M. Bickelhaupt, G. Frenking, Chem. Eur. J. 2006, 12, $9196-9216$

${ }^{12}$ M. Hermann, G. Frenking, Chem. Eur. J. 2016, 22, 4100-4108.

${ }^{13}$ NIST databank: https://webbook.nist.gov/chemistry/

14 N. Lewis, J. Am. Chem. Soc. 1916, 38, 762-786.

${ }^{15}$ C. A . Coulson, Proc. R. Soc. Lond. A 1939, 169, 413

${ }^{16}$ R. S. Mulliken, J. Chem. Phys. 1955, 23, 1833-1840.

${ }^{17}$ I. Mayer, J. Comput. Chem. 2007, 28, 204-221, and references therein.

${ }^{18}$ (a) C. Outeiral, M. A. Vincent, Á. M. Pendás, P. L. A. Popelier, Chem. Sci., 2018, 9, 5517-5529 ; (b) Á. M. Pendás, E. Francisco, Phys.Chem.Chem.Phys., 2018, 20, 16231-16237.

${ }^{19}$ (a) S. Shaik, H. S. Rzepa, R. Hoffmann, Angew. Chem. Int. Ed. 2013, 52, 3020; (b) Angew. Chem. 2013, 125, 3094 ; (c) D. Danovich, S. Shaik, R. Hoffmann, H. S. Rzepa, Angew. Chem. Int. Ed. 2013, 52, 5926; Angew. Chem. 2013, 125, 6040.(d) D. Danovich, P. C. Hiberty, W. Wu, H. S. Rzepa, S. Shaik, Chem. Eur. J. 2014, 20, 6220. (e) G. Frenking, M. Hermann, Angew. Chem. Int. Ed. 2013, 52, 2-6; (f) P.C. Hiberty, B. Braïda, Angew. Chem. Int. Ed. 2018, 57, 5994-6002.

${ }^{20}$ S. Shaik, D. Danovich, W. Wu, H. S. Rzepa, P. C. Hiberty, Nat.Chem. 2014, 4, 195-200.

${ }^{21}$ P. B. Karadakov, J. Kirsopp, Chem. Eur. J. 2017, 23, 12949-12954

${ }^{22}$ C. Zhu, X. Zhang, Y. Geng, X. Liu, Z. Su, J. Comput. Chem. 2019, 40, 1338-1343.

${ }^{23}$ D. W. O. de Sousa, M.A.C. Nascimento, J. Chem. Theory Comput. 2016, 12, 2234-2241.

${ }^{24}$ D.L. Cooper, R. Ponec, M. Kohout, Mol. Phys. 2016, 114, 1270-1284.

${ }^{25}$ W. Zou, D. Cremer, Chem. Eur. J. 2016, 22, 4087-4099.

${ }^{26}$ (a) J. S. Binkley, J. Am. Chem. Soc. 1984, 106, 603-609; (b) B.T. Colegrove, H. F. Schafer III, J. Phys. Chem. 1990, 94, 5593-5602. (c) M. Lein, A. Krapp, G. Frenking, J. Am. Chem. Soc. 2005, 127, 6290-6299.

${ }^{27}$ L. Sari, M. C. McCarthy, H. F. Schaefer III, P. Thaddeus, J. Am. Chem. Soc. 2003, 125(37) 11409-11417.

${ }^{28}$ D. A. Dixon, D. Feller, K. A. Peterson, J. L. Gole, J. Phys. Chem. A 2000, 104, 2326-2332 